\title{
Sophisten in Hellenismus und Kaiserzeit
}

\author{
Orte, Methoden und Personen der Bildungsvermittlung \\ Hrsg. v. Beatrice Wyss, Rainer Hirsch-Luipold u. Solmeng-Jonas Hirschi
}

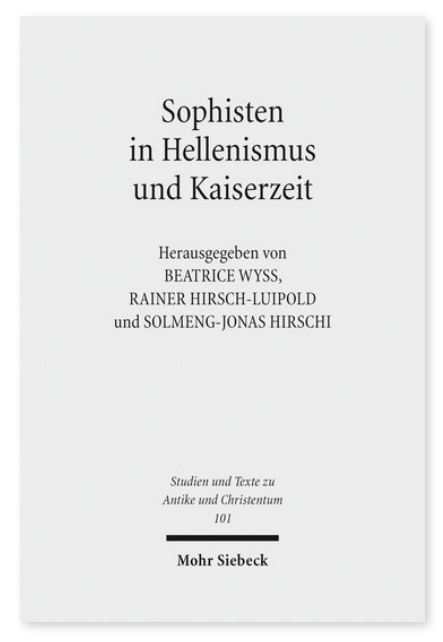

2017. VIII, 246 Seiten. STAC 101

ISBN 978-3-16-154592-4 DOI 10.1628/978-3-16-154592-4 eBook PDF 79,00€

ISBN 978-3-16-154591-7 fadengeheftete Broschur 79,00€
Der Forschung geläufig ist die Rede von einer ersten (5./4. Jh. v. Chr.) und der sog. Zweiten Sophistik (2. Jh. n. Chr). Aber auch die Literatur des Hellenismus und der frühen Kaiserzeit kennt zahlreiche Sophisten. Der Sophist, verstanden als (schlechter) Lehrer und Redner, Gegenspieler des Philosophen oder Vertreter der griechischen Bildung, bildet deshalb den Dreh-und Angelpunkt der Beiträge, die Schlaglichter auf Orte, Methoden und Personen der Bildungsvermittlung werfen. Sophisten wirken im Gymnasion, im Museion in Alexandreia, in Tempeln in Rom oder privaten Schulen in Ägypten und Judäa. Der vorliegende Band diskutiert neben diesen Orten die Methoden der Bildungsvermittlung und die soziale Herkunft der Lehrer. Weitere wichtige Aspekte sind die Konkurrenz als strukturierendes Element des Lebens eines Sophisten und das Bankett als Ort der Bildungsvermittlung. Die Beiträge zeigen, wie pagane und jüdische Denker, Platoniker und Stoiker Bildung als Weg zum richtigen Welt- und Gottesverständnis verstehen.

\section{Inhaltsübersicht}

Peter Scholz: Ein Ort bürgerlicher Mühe und Muße. Formen und Funktionen der Institution des griechischen Gymnasions im historischen Wandel - Stefanie Holder: Einrichtungen für Bildung und Lernen im kaiserzeitlichen Alexandria. War das Museion eine antike »Hochschule«? - Marco Galli: Le performances dei medici-sofisti. Luoghi della Seconda Sofistica a Roma Paul Schubert: L'activité des sophistes grecs en Égypte d'après le témoignage des papyrus - Johann Goeken: Orateurs et sophistes au banquet - Werner Urbanz: »Für alle, die Bildung suchen« (Sir 33,18). Aspekte frühjüdischer Bildung im Buch Jesus Sirach - Gregory E. Sterling: Philo's School. The Social Setting of Ancient Commentaries - Alexandra Michalewski: Pratiques du sophiste et du philosophe dans le Didaskalikos d'Alcinoos et le Prologue d'Albinus - Christian Fron: Der ewige

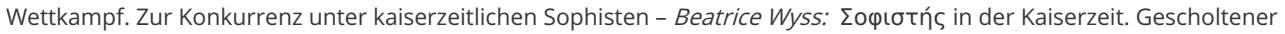
Lehrer oder gefeierter Redner?

Beatrice Wyss Geboren 1974; Studium der klassischen Philologie und Philosophie; 2008 Promotion; 2007-11 wissenschaftliche Mitarbeiterin DFG-Nachwuchsforschergruppe »Ratio Religionis«, Göttingen; 2011-14 DFG-Projekt »Sophist«, Göttingen und Bern; seit 2014 SNF-Projekt Erst-Edition »Giovanni del Virgilio, Paraphrasen zu Ovids Metamorphosen«, Bern.

Rainer Hirsch-Luipold Geboren 1967; seit 2011 Ordentlicher Professor für Neues Testament und Antike Religionsgeschichte an der Universität Bern; seit 2015 zusätzlich Extraordinary Professor an der Stellenbosch University (SA), Department of Ancient Studies.

https://orcid.org/0000-0002-6938-268X

Solmeng-Jonas Hirschi Geboren 1992; Studium der klassischen Philologie; 2016 MSt; 2012-14 Hilfassistenzen DFG-Projekt "Sophist«, Bern; seit 2016 DPhil in Classics, University of Oxford, Lincoln College.

Jetzt bestellen:

https://mohrsiebeck.com/buch/sophisten-in-hellenismus-und-kaiserzeit-9783161545924?no_cache=1 order@mohrsiebeck.com

Telefon: +49 (0)7071-923-17

Telefax: +49 (0)7071-51104 